\title{
Successful treatment for adrenocorticotropic hormone-independent macronodular adrenal hyperplasia with laparoscopic adrenalectomy: a case series
}

Toshiki Ito ${ }^{*}$, Yutaka Kurita ${ }^{1}$, Hitoshi Shinbo ${ }^{1}$, Atsushi Otsuka² ${ }^{2}$ Hiroshi Furuse², Soichi Mugiya ${ }^{2}$, Tomomi Ushiyama², Seiichiro Ozono ${ }^{2}$, Yutaka Oki ${ }^{3}$ and Kazuo Suzuki ${ }^{4}$

\begin{abstract}
Introduction: Adrenocorticotropic hormone-independent macronodular adrenal hyperplasia, characterized by bilateral macronodular adrenal hypertrophy and autonomous cortisol production, is a rare cause of Cushing's syndrome. Bilateral adrenalectomy is considered the standard treatment for adrenocorticotropic hormone-independent macronodular adrenal hyperplasia but obliges the patient to receive lifetime steroid replacement therapy subsequently, and may increase the patient's risk of adrenal insufficiency. These circumstances require surgeons to carefully consider operative strategies on an individual basis.

Case presentation: We performed successful laparoscopic adrenalectomy on four patients with adrenocorticotropic hormone-independent macronodular adrenal hyperplasia. Computed tomography scans showed bilateral adrenal enlargement in all patients. Case 1: a 56-year-old Japanese woman presented with obvious Cushing's symptoms during treatment for diabetes mellitus and hypertension. Case 2: a 37-year-old Japanese man also presented with Cushing's symptoms during treatment for diabetes mellitus and hypertension. These patients were diagnosed as Cushing's syndrome caused by adrenocorticotropic hormone-independent macronodular adrenal hyperplasia based on endocrinologic testing, and underwent bilateral laparoscopic adrenalectomy. Case 3: an 80-year-old Japanese woman was hospitalized due to unusual weight gain and heightened general fatigue, and was diagnosed as Cushing's syndrome caused by adrenocorticotropic hormone-independent macronodular adrenal hyperplasia. She underwent unilateral laparoscopic adrenalectomy due to high operative risk. Case 4: a 66-year-old Japanese man was discovered to have bilateral adrenal tumors on medical examination. He did not have Cushing's symptoms and was diagnosed as subclinical Cushing's syndrome due to suppressed adrenocorticotropic hormone serum levels and loss of cortisol circadian rhythm without abnormal levels of serum cortisol. He underwent unilateral laparoscopic adrenalectomy. During follow-up, serum cortisol levels were within the normal range in all cases, and serum adrenocorticotropic hormone levels were not suppressed. Further, cases with Cushing's syndrome experienced clinical improvement.
\end{abstract}

Conclusions: We were able to effectively treat adrenocorticotropic hormone-independent macronodular adrenal hyperplasia in patients with obvious Cushing's symptoms by laparoscopic bilateral adrenalectomy, which promptly improved symptoms. Further, unilateral adrenalectomy was effective for treating an older patient at high operative risk and a patient with subclinical Cushing's syndrome.

\footnotetext{
* Correspondence: t-ito0301@hotmail.co.jp

'Department of Urology, JA Shizuoka Kohseiren Enshu Hospital, 1-1-1 Chuo,

Naka-ku, Hamamatsu, Shizuoka 430-0929, Japan

Full list of author information is available at the end of the article
} 


\section{Introduction}

Adrenocorticotropic hormone (ACTH)-independent macronodular adrenal hyperplasia (AIMAH), an impairment demonstrated by bilateral macronodular adrenal hypertrophy and autonomous cortisol production, is a rare cause of Cushing's syndrome. Although bilateral adrenalectomy is considered the standard treatment for AIMAH [1,2], patients receiving this treatment are subsequently obliged to receive lifetime steroid replacement therapy and may be susceptible to adrenal insufficiency. Given these concerns, the operative strategy for treating AIMAH must be considered carefully for each individual case.

Here we report the surgical and clinical aspects of four cases of AIMAH that were treated by laparoscopic adrenalectomy, including two requiring bilateral adrenalectomy.

\section{Case presentations}

We performed adrenalectomies on four consecutive patients with AIMAH from 1999 to 2010. The patients' clinical and biochemical findings are summarized in Table 1. Enhanced computed tomography (CT) showed bilateral adrenal enlargement with slight enhancement (Figure 1), and adrenal scintigraphy revealed bilateral uptake of ${ }^{131}$ I-norcholesterol was observed in all patients.

\section{Case 1}

A 56-year-old Japanese woman presented with several symptoms characteristic of Cushing's syndrome, including moon face and central obesity, during treatment for diabetes mellitus and hypertension. She was diagnosed as Cushing's syndrome caused by AIMAH due to autonomous production of adrenal cortisol, which was accompanied by suppressed serum ACTH levels (<5.0pg/ $\mathrm{mL}$ ) and a loss of cortisol circadian rhythm. She underwent laparoscopic bilateral adrenalectomy because of her overt Cushing's symptoms. The operative procedure in this case has been described by Shinbo et al. [3]. Cortisol replacement therapy was started immediately upon completion of surgery.

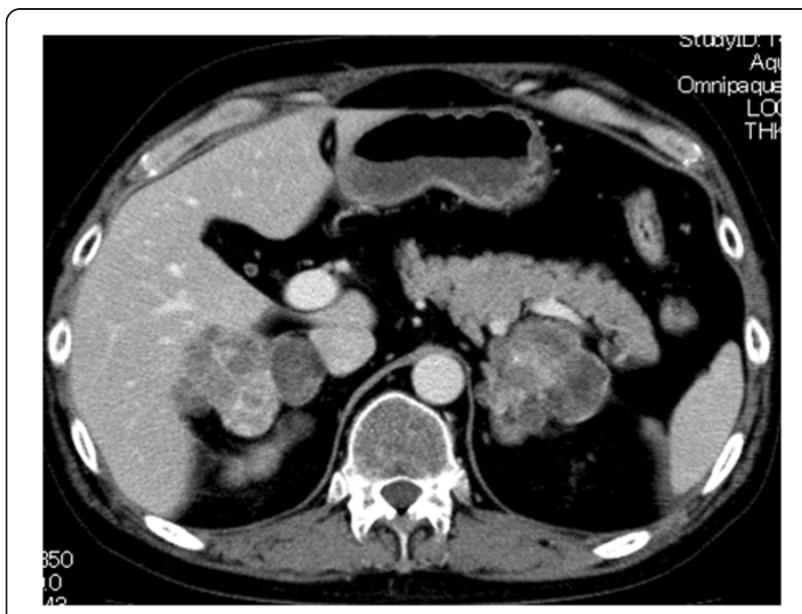

Figure 1 Abdominal computed tomography in patient 2 showing bilateral multinodular adrenal enlargement with maximum diameters of $8.5 \mathrm{~cm}$ and $10.5 \mathrm{~cm}$ on the right and left sides, respectively.

\section{Case 2}

A 37-year-old Japanese man presented with severe Cushing's symptoms during treatment for diabetes mellitus and hypertension. Symptoms included moon face, central obesity, and muscle weakness. He underwent laparoscopic bilateral adrenalectomy and cortisol replacement therapy post-operatively (Figure 2).

\section{Case 3}

An 80-year-old Japanese woman was hospitalized because of unusual weight gain (about $10 \mathrm{~kg}$ over about two years) and general fatigue. Upon admission, she was diagnosed as Cushing's syndrome. She underwent unilateral adrenalectomy due to high operative risk. We based our decision on the side to operate on based on which gland was larger according to CT scan findings.

\section{Case 4}

A 66-year-old Japanese man was incidentally discovered to have bilateral adrenal tumors but no Cushing's symptoms. The endocrinological data showed a normal level of cortisol $(10.4 \mu \mathrm{g} / \mathrm{dL})$ with a suppressed serum ACTH

Table 1 Clinical and biochemical findings

\begin{tabular}{|c|c|c|c|c|c|c|c|c|}
\hline \multirow[t]{2}{*}{ Case } & \multirow[t]{2}{*}{ Age } & \multirow[t]{2}{*}{ Gender } & \multirow[t]{2}{*}{$\begin{array}{c}\text { Body mass } \\
\text { index }\left(\mathrm{kg} / \mathrm{m}^{2}\right)\end{array}$} & \multirow[t]{2}{*}{$\begin{array}{l}\text { Size of adrenal } \\
\text { gland }(\mathrm{L} / \mathrm{R}, \mathrm{cm})\end{array}$} & \multirow[t]{2}{*}{$\begin{array}{l}\text { Cushing's } \\
\text { symptoms }\end{array}$} & \multicolumn{2}{|c|}{$\begin{array}{c}\text { Serum cortisol ( } \mu \mathrm{g} / \mathrm{dL}) \\
\text { (basal values: } 5.3 \text { to } 11.0 \text { ) }\end{array}$} & \multirow{2}{*}{$\begin{array}{c}\text { Plasma } \\
\text { adrenocorticotropic } \\
\text { hormone (pg/mL) } \\
\text { (normal values: } 7.2 \\
\text { to } 63.3 \text { ) }\end{array}$} \\
\hline & & & & & & At 8 a.m. & At 11 p.m. & \\
\hline 1 & 56 & $F$ & 21.2 & $6.5 / 5.5$ & + & 21.5 & 20.4 & $<5.0$ \\
\hline 2 & 37 & $M$ & 26.6 & $10.5 / 8.5$ & + & 34.1 & 28.7 & $<5.0$ \\
\hline 3 & 80 & $\mathrm{~F}$ & 21.7 & $4.0 / 3.5$ & + & 14.2 & 16.2 & $<5.0$ \\
\hline 4 & 66 & $M$ & 29.6 & $6.0 / 8.5$ & - & 10.4 & 10.7 & $<5.0$ \\
\hline
\end{tabular}



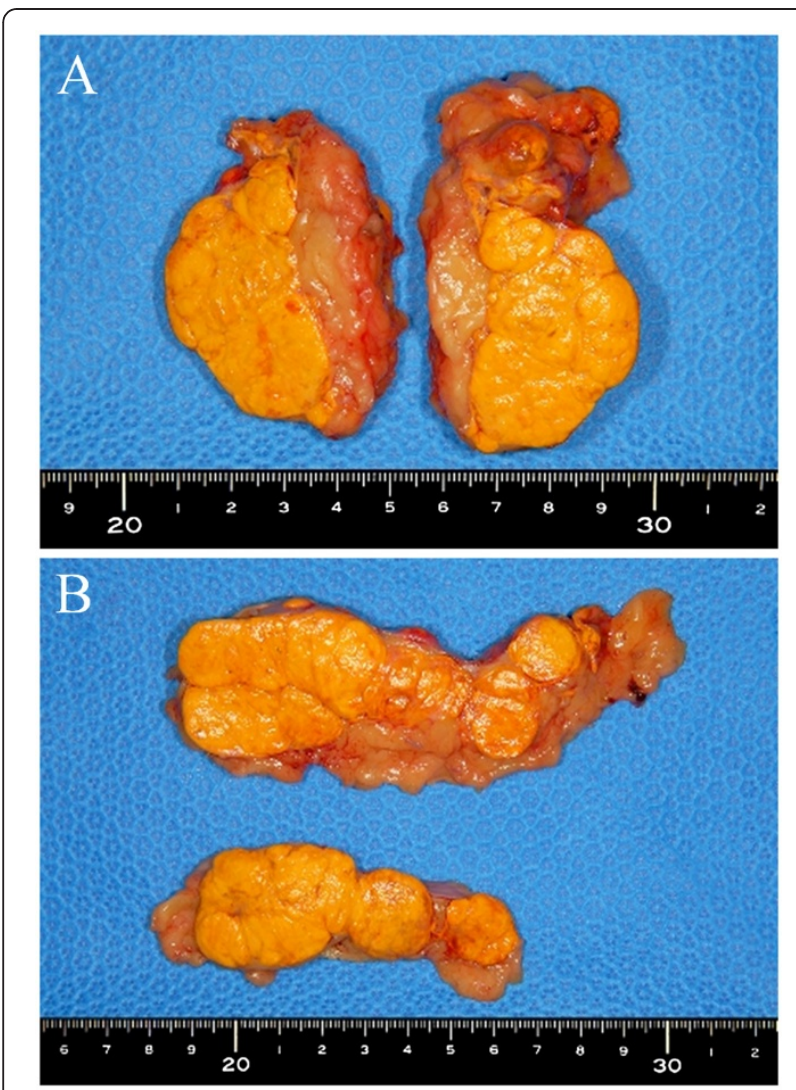

Figure 2 Macroscopic appearance of the adrenal glands of patient 2. (A) The right gland weighed $141 \mathrm{~g}$ and measured $85 \times 60 \times 40 \mathrm{~mm}$. (B) The left gland weighed $145 \mathrm{~g}$ and measured $105 \times 45 \times 40 \mathrm{~mm}$. Both glands exhibited many macronodules on the exposed surface.

level $(<5.0 \mathrm{pg} / \mathrm{mL})$, which showed neither a cortisol circadian rhythm nor suppression by dexamethasone administration $(9.1 \mu \mathrm{g} / \mathrm{dL}$ after $1 \mathrm{mg} ; 16.9 \mu \mathrm{g} / \mathrm{dL}$ after $8 \mathrm{mg})$. He underwent right laparoscopic adrenalectomy due to subclinical Cushing's syndrome. In this case, the right adrenal gland was removed, because adrenal venous sampling revealed that cortisol production from the right gland was much greater than from the left (right: $38.9 \mu \mathrm{g} / \mathrm{dL}$; left: $20.3 \mu \mathrm{g} / \mathrm{dL})$.

The surgical procedures and results are summarized in Table 2. The duration of the operations for patients 1 and 2 included the time required to change the patient's position. The estimated blood loss was for patient 1 was $350 \mathrm{~mL}$ and negligible in the others. All patients were able to walk and receive oral nutrient intake by postoperative day 2 . Hydrocortisone was administered intravenously to patients 1 and 2 starting on the day of the operation. The drug was administered orally after the patients stared taking meals orally. The dose was tapered to 15 or $20 \mathrm{mg}$ /day until discharge, which prolonged the length of their hospitalization. No conversions to open surgery were performed, and no severe complications occurred during the post-operative period.

Clinical courses and outcomes are summarized in Table 3. Clinical improvements, such as disappearance of moon face, central obesity, and muscle weakness were evident in patients 1,2 , and 3. Patient 4 remained asymptomatic for Cushing's syndrome during follow-up. Serum cortisol levels have remained within normal ranges and serum ACTH levels were unsuppressed in all cases during follow-up.

\section{Discussion}

Bilateral adrenalectomy and steroid replacement therapy is considered the standard treatment for AIMAH $[1,2]$. Several cases of successful laparoscopic bilateral adrenalectomy for AIMAH have been reported [3-6], and each involved little blood loss during surgery. Laparoscopic adrenalectomy is less invasive than open surgery for treating AIMAH and may prevent a number of postoperative complications due to impaired glucose tolerance and immunodeficiency. However, treatment of AIMAH requires considerable skill given the impressive size and fragility of adrenal tumors.

Although we opted for a bilateral approach here, several patients have been treated successfully after receiving only medical treatment or subtotal or unilateral adrenalectomy [7-9]. The rationale for implementing these treatments was to avoid impairing our patients' quality of life due to the risk of critical adrenal insufficiency after bilateral adrenalectomy. Two recent reports note that unilateral adrenalectomy of the larger gland with AIMAH resulted in improvement in Cushing's symptoms after a mean follow-up

Table 2 Operative procedures and results

\begin{tabular}{|c|c|c|c|c|c|c|c|}
\hline Case & $\begin{array}{c}\text { Site of } \\
\text { adrenalectomy }\end{array}$ & $\begin{array}{l}\text { Operation } \\
\text { time (minutes) }\end{array}$ & $\begin{array}{l}\text { Blood } \\
\text { loss }(g)\end{array}$ & $\begin{array}{l}\text { Weight of adrenal } \\
\text { gland }(L / R, g)\end{array}$ & $\begin{array}{c}\text { Discharge } \\
\text { (post-operative day) }\end{array}$ & $\begin{array}{c}\text { Dosage of hydrocortisone } \\
\text { at discharge (mg/day) }\end{array}$ & Complications \\
\hline 1 & Bilateral & 424 & 350 & $57 / 51$ & 20 & 20 & Surgical site infection \\
\hline 2 & Bilateral & 520 & Negligible & $145 / 141$ & 18 & 15 & None \\
\hline 3 & Left & 134 & Negligible & $30 /-$ & 7 & None & None \\
\hline 4 & Right & 244 & Negligible & $-/ 50$ & 6 & None & None \\
\hline
\end{tabular}


Table 3 Clinical course and outcomes

\begin{tabular}{|c|c|c|c|c|c|c|}
\hline \multirow[t]{2}{*}{ Case } & \multirow{2}{*}{$\begin{array}{l}\text { Follow-up } \\
\text { duration } \\
\text { (months) }\end{array}$} & \multirow{2}{*}{$\begin{array}{l}\text { Dosage of } \\
\text { hydrocortisone } \\
\text { (mg/day) }\end{array}$} & \multirow{2}{*}{$\begin{array}{l}\text { Cushing's } \\
\text { symptoms }\end{array}$} & \multirow{2}{*}{$\begin{array}{c}\text { Body mass } \\
\text { index }\left(\mathrm{kg} / \mathrm{m}^{2}\right)\end{array}$} & \multicolumn{2}{|c|}{ Endocrinological examination } \\
\hline & & & & & $\begin{array}{l}\text { Serum cortisol at } 8 \text { a.m. }(\mu \mathrm{g} / \mathrm{dL} \text { ) } \\
\text { (normal values: } 5.3 \text { to } 11.0 \text { ) }\end{array}$ & $\begin{array}{c}\text { Plasma adrenocorticotropic } \\
\text { hormone (pg/mL) } \\
\text { (normal values: } 7.2 \text { to } 63.3 \text { ) }\end{array}$ \\
\hline 1 & 146 & 15 & Improved & 20.5 & 2.7 & 25.7 \\
\hline 2 & 35 & 15 & Improved & 24.2 & 1.1 & 50.1 \\
\hline 3 & 24 & None & Improved & 20.3 & 11.2 & 7.9 \\
\hline 4 & 90 & None & Subclinical & 28.3 & 14.6 & 4.1 \\
\hline
\end{tabular}

time of 53 or 78.8 months $[10,11]$. However, the efficacy of unilateral adrenalectomy for AIMAH remains controversial because the mean patient age in these reports is 52.6 years, clearly insufficient for long-term assessment. We reasoned, therefore, that if a patient receives a second operation to remove the remaining gland when Cushing's syndrome recurs during followup, unilateral adrenalectomy might also be effective in selected cases such as those reported here. In patients with subclinical AIMAH, the decision regarding therapy should take into account normalization of cortisol excess. Unilateral adrenalectomy is the treatment of choice, as well as medical treatment or subtotal or unilateral adrenalectomy, for normalization of cortisol excess. However, careful attention must be paid after unilateral adrenalectomy, as the criteria and long-term prognosis of this procedure in subclinical AIMAH have not been well established. If unilateral adrenalectomy is performed, determination of the surgical site should be based on asymmetrical adrenal enlargement or adrenal venous sampling analysis; the gland more strongly influencing the patient's condition should be removed.

\section{Conclusions}

In our experience, laparoscopic bilateral adrenalectomy for AIMAH with obvious Cushing's symptoms was effective in rapidly improving symptoms when performed by an experienced surgical team. Further, unilateral adrenalectomy can also be effective when the patient is older and subject to high operative risk or does not present with clinical symptoms. Because long-term prognosis associated with this surgical technique remains controversial, strategies for treating AIMAH must be carefully considered on a case-by-case basis.

\section{Consent}

Written informed consent was obtained from all patients for publication of this case report and accompanying images. A copy of the written consent is available for review by the Editor-in-Chief of this journal.
Competing interests

The authors declare that they have no competing interests.

\section{Authors' contributions}

$\mathrm{TI}$ and $\mathrm{YK}$ wrote the manuscript. TI, YK, AO, HS, HF, SM, TU, and KS cared for our patients. YO performed endocrinological examinations and patient management. All authors reviewed the report and approved the final version of the manuscript.

\section{Author details}

'Department of Urology, JA Shizuoka Kohseiren Enshu Hospital, 1-1-1 Chuo, Naka-ku, Hamamatsu, Shizuoka 430-0929, Japan. ²Department of Urology, Hamamatsu University School of Medicine, 1-20-1 Handayama, Higashi-ku, Hamamatsu, Shizuoka 431-3192, Japan. ${ }^{3}$ Department of Endocrinology \& Metabolism, Hamamatsu University School of Medicine, 1-20-1 Handayama, Higashi-ku, Hamamatsu, Shizuoka 431-3192, Japan. ${ }^{4}$ Department of Urology, Institute of Minimally Invasive Surgery, Shintoshi Hospital, 703 Nakaizumi, Iwata, Shizuoka 438-0078, Japan.

Received: 26 January 2012 Accepted: 2 August 2012

Published: 18 September 2012

\section{References}

1. Swain JM, Grant CS, Schlinkert RT, Thompson GB, van Heerden JA, Lloyd RV, Young WF: Corticotropin-independent macronodular adrenal hyperplasia: a clinicopathologic correlation. Arch Surg 1998, 133:541-546.

2. Shinojima H, Kakizaki H, Usuki T, Harabayashi T, Ameda K, Koyanagi T: Clinical and endocrinological features of adrenocorticotropic hormoneindependent bilateral macronodular adrencortical hyperplasia. J Urol 2001, 166:1639-1642.

3. Shinbo H, Suzuki K, Sato T, Kageyama S, Ushiyama T, Fujita K: Simultaneous bilateral laparoscopic adrenalectomy in ACTH-independent macronodular adrenal hyperplasia. Int J Urol 2001, 8:315-318.

4. Imai T, Kikumori T, Shibata A, Fujiwara M, Nakao A: Laparoscopic bilateral adrenalectomy for Cushing's syndrome due to ACTH-independent macronodular adrenocortical hyperplasia. Biomed Pharmacother 2002, 56:120s-125s.

5. Muramaki M, Okada H, Sakai Y, Gotoh A, Fujisawa M, Kamidono S, Kawabata G: Adrenocorticotropin-independent macronodular adrenal hyperplasia treated by simultaneous bilateral laparoscopic adrenalectomy. Int J Urol 2003, 10:449-452.

6. Kubo N, Onoda N, Ishikawa T, Ogawa Y, Takashima T, Yamashita Y, Tahara H, Inaba M, Hirakawa K: Simultaneous bilateral laparoscopic adrenalectomy for adrenocorticotropic hormone-independent macronodular adrenal hyperplasia: report of a case. Surg Today 2006, 36:642-646.

7. Omori N, Nomura K, Omori K, Takano K, Obara T: Rational, effective metyrapone treatment of $\mathrm{ACTH}$-independent bilateral macronodular adrenocortical hyperplasia (AIMAH). Endocr J 2001, 48:665-669.

8. Ogura M, Kusaka I, Nagasaka S, Yatagai T, Shinozaki S, Itabashi N, Nakamura T, Yokohama M, Ishikawa S, Ishibashi S: Unilateral adrenalectomy improves insulin resistance and diabetes mellitus in a patient with ACTHindependent macronodular adrenal hyperplasia. Endocr J 2003, 50:715-721.

9. Kageyama Y, Ishizaka K, Iwashina M, Sasano H, Kihara K: A case of ACTHindependent bilateral macronodular adrenal hyperplasia successfully 
treated by subtotal resection of the adrenal glands: four-year follow-up. Endocr J 2002, 49:227-229.

10. Lamas C, Alfaro JJ, Lucas T, Lecumberri B, Barcelo B, Estrada J: Is unilateral adrenalectomy an alternative treatment for ACTH-independent macronodular adrenal hyperplasia?: long-term follow-up of four cases. Eur J Endocrinol 2002, 146:237-240.

11. lacobone M, Albiger N, Scaroni C, Mantero F, Fassina A, Viel G, Frego M, Favia G: The role of unilateral adrenalectomy in ACTH-independent macronodular adrenal hyperplasia (AIMAH). World I Surg 2008, 32:882-889.

doi:10.1186/1752-1947-6-312

Cite this article as: Ito et al:: Successful treatment for

adrenocorticotropic hormone-independent macronodular adrenal hyperplasia with laparoscopic adrenalectomy: a case series. Journal of Medical Case Reports 2012 6:312.

\section{Submit your next manuscript to BioMed Central and take full advantage of:}

- Convenient online submission

- Thorough peer review

- No space constraints or color figure charges

- Immediate publication on acceptance

- Inclusion in PubMed, CAS, Scopus and Google Scholar

- Research which is freely available for redistribution 